Article

\title{
Role of Daptomycin in the Induction and Persistence of the Viable but Non-Culturable State of Staphylococcus Aureus Biofilms
}

\author{
Sonia Pasquaroli ${ }^{1}$, Barbara Citterio ${ }^{2}$, Andrea Di Cesare ${ }^{1}$, Mehdi Amiri ${ }^{1}$, Anita Manti ${ }^{3}$, \\ Claudia Vuotto ${ }^{4}$ and Francesca Biavasco ${ }^{1, *}$
}

1 Department of Life and Environmental Sciences, Polytechnic University of Marche, Ancona 60131, Italy; E-Mails: s.pasquaroli@univpm.it (S.P.); andrix.di.cesare@alice.it (A.D.C.); amiri.m1983@gmail.com (M.A.)

2 Department of Biomolecular Sciences, Sect. Toxicological, Hygiene, and Environmental Sciences, University of Urbino Carlo Bo, Urbino 61029, Italy; E-Mail: barbara.citterio@uniurb.it

3 Department of Earth, Life and Environmental Sciences, University of Urbino Carlo Bo, Urbino 61029, Italy; E-Mail: anita.manti@uniurb.it

4 Microbial Biofilm Laboratory, IRCCS Fondazione Santa Lucia, Rome 00179, Italy;

E-Mail: c.vuotto@hsantalucia.it

* Author to whom correspondence should be addressed; E-Mail: f.biavasco@univpm.it; Tel.: +39-071-220-4622; Fax: +39-071-220-4650.

Received: 26 June 2014; in revised form: 22 August 2014 / Accepted: 12 September 2014 / Published: 18 September 2014

\begin{abstract}
We have recently demonstrated that antibiotic pressure can induce the viable but non-culturable (VBNC) state in Staphylococcus aureus biofilms. Since dormant bacterial cells can undermine anti-infective therapy, a greater understanding of the role of antibiotics of last resort, including daptomycin, is crucial. Methicillin-resistant S. aureus 10850 biofilms were maintained on non-nutrient (NN) agar in the presence or absence of the MIC of daptomycin until loss of culturability. Viable cells were monitored by epifluorescence microscopy and flow cytometry for 150 days. All biofilms reached non-culturability at 40 days and showed a similar amount of viable cells; however, in biofilms exposed to daptomycin, their number remained unchanged throughout the experiment, whereas in those maintained on $\mathrm{NN}$ agar alone, no viable cells were detected after 150 days. Gene expression assays showed that after achievement of non-culturability, 16S rDNA and mecA were expressed by all biofilms, whereas glt expression was found only in daptomycin-exposed
\end{abstract}


biofilms. Our findings suggest that low daptomycin concentrations, such as those that are likely to obtain within biofilms, can influence the viability and gene expression of non-culturable $S$. aureus cells. Resuscitation experiments are needed to establish the VBNC state of daptomycin-exposed biofilms.

Keywords: Staphylococcus aureus biofilm; VBNC; daptomycin

\section{Introduction}

Biofilm production protects bacteria from a number of stress conditions [1,2], it promotes antibiotic resistance [2,3] and is often related to the onset of persistent infections [1,2], especially those associated with indwelling medical devices [3,4].

The continuous increase in antimicrobial resistance hampers the treatment of infections. The success of multidrug-resistant Gram-positive pathogens, such as methicillin-resistant Staphylococcus aureus (MRSA) [5-7], vancomycin-resistant enterococci (VRE) [8] and coagulase-negative staphylococci [9], emphasizes the need for new antimicrobials with alternative mechanisms of action. Daptomycin is a cyclic anionic lipopeptide antibiotic produced by Streptomyces roseosporus that, in the EU, has been approved to treat skin and soft-tissue infections since 2006 [10]. Daptomycin has bactericidal activity against Gram-positive bacteria, including MRSA [11,12] and VRE [13], and is currently the last line of defense against severe Gram-positive infections. It has a unique, but not completely elucidated, mechanism of action, where a calcium-dependent dissipation of membrane potential leads to the release of intracellular ions from the cell and, ultimately, to death [14]. Daptomycin is effective in treating skin infections, endocarditis and bacteremia [15] and in counteracting biofilm-based infections associated with medical devices [16,17], which frequently require combination therapy [18]. The combination with rifampicin or beta-lactams has been reported to be effective in treating biofilm-related enterococcal [18] and staphylococcal [12] infections.

The viable but non-culturable (VBNC) state is a survival strategy characterized by low-level metabolic activity and bacterial growth failure on standard media [19]. It protects bacterial cells from environmental stress, such as nutrient depletion, changes in temperature, $\mathrm{pH}$ or salinity [20], and presence of antibiotics [21]. The VBNC state has been reported for several human pathogens [19], including biofilm-producing staphylococci [21]. The critical feature of cells in the VBNC state is their ability to regain culturability in the presence of resuscitation-promoting factors [22]. In a recent in vitro study by our group, vancomycin and quinupristin-dalfopristin, which are often used to treat biofilm-associated chronic infections [23], have been demonstrated to promote the emergence of persistent VBNC forms in S. aureus biofilms [22]. These findings prompted us to establish whether daptomycin, which is considered as a last line of defense antibiotic, also induces the VBNC state. 


\section{Results and Discussion}

\subsection{Biofilm Production, Stress Exposure and Non-Culturability}

The strong biofilm producer, S. aureus 10850 [21,24], was analyzed for susceptibility to daptomycin by MIC determination and showed low-level resistance with a MIC value of $2 \mu \mathrm{g} / \mathrm{mL}$ (European Committee on Antimicrobial Susceptibility Testing (EUCAST) susceptibility breakpoint $\leq 1 \mu \mathrm{g} / \mathrm{mL})$.

To induce the VBNC state, S. aureus 10850 biofilms developed on membrane filters were placed on non-nutrient (NN) agar plates without or with daptomycin (at a concentration equal to the MIC) to induce the largest possible amount of VBNC cells [21] and incubated at $37^{\circ} \mathrm{C}$. Culturability was tested every two days.

All biofilms reached non culturability in 40 days. They were then detached from the filters, stained by the live/dead method, and examined for viable cells by epifluorescence microscopy. All filters were culture-negative and contained green coccoid cells whose average counts were $3.8 \times 10^{4} / \mathrm{mL}$ (starved biofilms) and $2.7 \times 10^{4} / \mathrm{mL}$ (starved + daptomycin-exposed biofilms).

\subsection{Persistence of the VBNC State}

After achievement of non-culturability on the 40th day, the persistence of the VBNC state was monitored by epifluorescence microscopy for 150 days in biofilms maintained on NN agar plates without or with daptomycin (Figure 1). Live/dead staining of a non-culturable daptomycin-exposed biofilm on the 15th day followed by flow cytometry demonstrated a viable subpopulation (Table 1), whose abundance was comparable to that documented by epifluorescence counts (differences $\leq 0.5 \log$ ).

The number of viable cells remained substantially unchanged throughout the experiment in starved and daptomycin-exposed biofilms; in those maintained on $\mathrm{NN}$ agar alone, it did not change significantly over the first 90 days, but no viable cells were left on the 150th day (Figure 1, Table 1).

These findings indicate that daptomycin exposure extended the viability of non-culturable cells compared with starvation alone, whereas nutrient depletion rather seemed to give rise to premortem VBNC forms, supporting previous data by our group [21]. 
Figure 1. Epifluorescence counts after live-dead staining of viable and total cells in detached non-culturable $S$. aureus 10850 biofilms exposed to nutrient depletion with (D) or without $(\mathrm{NN})$ daptomycin. Counts were performed at various intervals (0-150 days) from the loss of culturability. The results are the means of two counts. VBNC, viable but non-culturable.

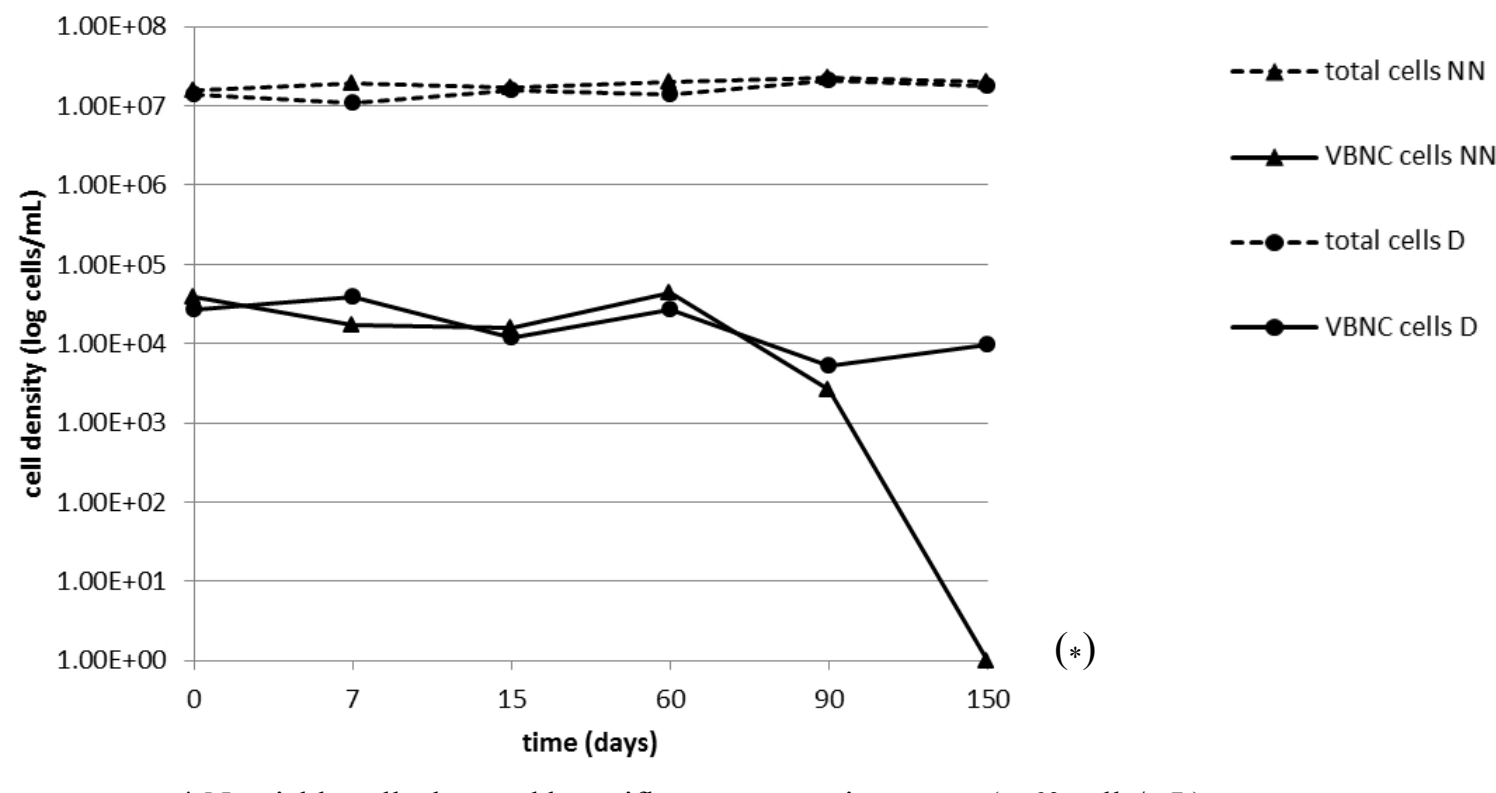

* No viable cells detected by epifluorescence microscopy (<60 cells $/ \mathrm{mL})$.

Table 1. Total and viable cells counts in biofilms exposed to nutrient depletion or nutrient depletion with daptomycin.

\begin{tabular}{cccc}
\hline \multirow{2}{*}{ Stress Condition } & $\begin{array}{c}\text { Days Since } \\
\text { Achievement of } \\
\text { Non-Culturability }\end{array}$ & Total & Cells/mL \\
\cline { 3 - 4 } & 0 & $1.6 \times 10^{7}$ & $3.8 \times 10^{4}$ \\
& 7 & $1.9 \times 10^{7}$ & $1.7 \times 10^{4}$ \\
Nutrient depletion & 15 & $1.7 \times 10^{7} / 1.5 \times 10^{8 *}$ & $1.6 \times 10^{4} / 8.2 \times 10^{4} *$ \\
& 60 & $2.0 \times 10^{7}$ & $4.4 \times 10^{4}$ \\
& 90 & $2.3 \times 10^{7}$ & $2.6 \times 10^{3}$ \\
Nutrient depletion & 150 & $2.0 \times 10^{7}$ & $<60$ \\
+ daptomycin & 0 & $1.4 \times 10^{7}$ & $2.7 \times 10^{4}$ \\
& 7 & $1.1 \times 10^{7}$ & $3.9 \times 10^{4}$ \\
& 15 & $1.6 \times 10^{7} / 1.4 \times 10^{8 *}$ & $1.2 \times 10^{4} / 7.6 \times 10^{4} *$ \\
& 60 & $1.4 \times 10^{7}$ & $2.7 \times 10^{4}$ \\
& 90 & $2.1 \times 10^{7}$ & $5.3 \times 10^{3}$ \\
& 150 & $1.8 \times 10^{7}$ & $9.8 \times 10^{3}$ \\
\hline
\end{tabular}

* Flow cytometric analysis. 


\subsection{Gene Expression of VBNC Cells}

The presence of viable subpopulations after loss of culturability was tested by gene expression experiments. Non-culturable biofilms, either starved and starved and daptomycin-exposed, were tested for the expression of two S. aureus housekeeping genes, 16S rDNA and glt (coding for glutamate synthase). Aliquots of non-culturable biofilms detached 0, 7, 15 and 60 days from the loss of culturability were analyzed by real-time RT-PCR. The expression of $16 \mathrm{~S}$ rRNA was detected in all biofilms tested, whereas glt was expressed exclusively in daptomycin-exposed biofilms at 0,7 and 15 days (Table 2). Since 16S rRNA quantification is considered a reliable assay of viability [25], these findings support the epifluorescence and cytofluorimetric evidence of the presence of VBNC cells, in line with data from an earlier study by our group [21]. Given that glutamate synthase is involved in the incorporation of ammonium ions into organic compounds, which is a key step in amino acid production [26], it could have a role in the persistence of a true viable state in non-culturable biofilms via continued amino acid uptake and incorporation [27].

The ability of non-culturable biofilms to express virulence and antibiotic resistance genes was explored by further real-time RT-PCR assays targeting the thermonuclease (nuc) and the methicillin resistance penicillin binding protein $2 \mathrm{a}$ (PBP2a) ( $\mathrm{mecA}$ ) genes. nuc expression was detected in none of the biofilms analyzed and mecA expression in all of them (Table 2). These findings suggest that thermonuclease may not be essential for biofilm survival in vitro. Moreover, the paucity of metabolically active cells suggests that its expression could be inhibited by quorum sensing [28]. Conversely, the mecA gene encodes a PBP involved in cell wall formation [5] that could play an important role in maintaining the wall of VBNC cells intact and functional.

Table 2. Expression of key genes in non-culturable $S$. aureus 10850 biofilms exposed to nutrient depletion with or without daptomycin.

\begin{tabular}{ccccccc}
\hline \multirow{2}{*}{ Stress Condition } & Time from non & \multicolumn{5}{c}{ Gene Analysis } \\
\cline { 3 - 6 } & Culturability & 16SrDNA & glt & nuc & mec $\boldsymbol{A}$ \\
\hline \multirow{3}{*}{ Nutrient depletion } & $\mathrm{T} 0$ & + & $\mathrm{ND}$ & $\mathrm{ND}$ & $\mathrm{ND}$ \\
& $\mathrm{T} 7$ & + & - & - & + \\
& $\mathrm{T} 15$ & + & - & - & + \\
& $\mathrm{T} 60$ & + & - & - & + \\
\hline \multirow{3}{*}{ Nutrient depletion +} & $\mathrm{T} 0$ & + & $\mathrm{ND}$ & $\mathrm{ND}$ & $\mathrm{ND}$ \\
daptomycin & $\mathrm{T} 7$ & + & + & - & + \\
& $\mathrm{T} 15$ & + & + & - & + \\
& $\mathrm{T} 60$ & + & - & - & + \\
\hline
\end{tabular}

ND: not determined.

Taken together, the findings of our experiments seem to indicate that daptomycin acts as an inducer of the VBNC state of $S$. aureus by modulating gene expression, activating or repressing the transcription of specific genes. This effect may be explained by a poor penetration of daptomycin and the achievement of subinhibitory concentrations in the deep layers of the $S$. aureus biofilm matrix.

Indeed, low concentrations of a number of antibiotics exert biological activities other than inhibition, with major effects on transcription patterns [29]. The phenomenon, known as hormesis, involves 
biological responses to environmental signals or stress conditions that are characterized by biphasic dose-response relationships exhibiting low-dose stimulation and high-dose inhibition [30]. Subinhibitory concentrations of antimicrobial peptides, such as the cyclic lipopeptide daptomycin, which causes rapid membrane depolarization and potassium ion efflux, can thus increase the transcription levels of osmoprotectants, countering the osmotic stress, and downregulate the ribose transport system [30]. Given that ribose is a key element for ATP and RNA synthesis, this condition could be a stress factor for bacterial cells, contributing to VBNC state induction and persistence.

Since increased cell wall thickness is typical of the VBNC state [19], it may be hypothesized that low daptomycin concentrations stimulate the synthesis of peptidoglycan genes, as reported for imipenem in studies of the Pseudomonas aeruginosa transcriptome [30]. On the other hand, an involvement of daptomycin in the regulation of cell wall synthesis is quite likely, given that PBPs are membrane proteins. A role for daptomycin may also be inferred based on its reported synergism with beta-lactams against staphylococcal biofilms [12].

\section{Experimental Section}

\subsection{Bacterial Strains, Media, Antibiotics and Enzymes}

The strong biofilm producer, S. aureus 10850 [24], was routinely grown in tryptic soy broth (TSB) or agar (TSA) (Oxoid, Basingstoke, U.K.), supplemented with 1\% (v/v) glucose (TSBG or TSAG) to promote biofilm production. M9 minimal medium without glucose was used as NN agar in VBNC induction assays, as described by Pasquaroli et al. [21]. The following antibiotics and enzymes were used: daptomycin (Cubicin, Novartis Pharma SpA, Italy) and lysozyme and lysostaphin (Sigma-Aldrich St Louis, MO, USA).

\subsection{MIC Determination}

The MIC of daptomycin was determined by a broth microdilution method, and S. aureus susceptibility was defined according to the European Committee on Antimicrobial Susceptibility Testing (EUCAST) breakpoints [31]. The test medium was MHII broth (Becton-Dickinson, Milan, Italy) supplemented with $\mathrm{CaCl}_{2}$ (calcium chloride; Merck $\mathrm{KGaA}$, Darmstadt, Germany) to a final $\mathrm{Ca}^{2+}$ concentration of $50 \mu \mathrm{g} / \mathrm{mL}$. S. aureus ATCC 29213 was used as the control strain.

\subsection{Biofilm Production, Stress Exposure and Culturability Assays}

In vitro biofilm production, stress exposure and culturability assays were performed as described by Pasquaroli et al. [21]. Briefly, $100 \mu \mathrm{L}$ of a late-log culture of $S$. aureus 10850 grown in TSBG was spotted on $0.22-\mu \mathrm{m}$ sterile nitrocellulose filters (Millipore Corporation, Billerica, MA, USA); the filters were placed onto TSAG plates for $48 \mathrm{~h}$ at $37^{\circ} \mathrm{C}$ to allow biofilm development at the filter-air interface. They were then moved to $\mathrm{NN}$ agar plates, unsupplemented or supplemented with daptomycin $(2 \mu \mathrm{g} / \mathrm{mL})$, and incubated at $37{ }^{\circ} \mathrm{C}$ until loss of culturability. Filter cultures were transferred weekly to fresh agar plates without washing. Culturability was assessed every 2 days by placing a loop of filter cultures in TSB and onto TSA, followed by incubation for $48 \mathrm{~h}$ at $37^{\circ} \mathrm{C}$. Filter 
cultures testing negative on culturability assays were placed in $5 \mathrm{~mL}$ saline, detached by 3 cycles of sonication and vortexing, washed and resuspended in the same volume of saline.

\subsection{Epifluorescence Microscopy and Flow Cytometry}

Epifluorescence microscopy and flow cytometry counts were performed as described previously [21]; each count was carried out in duplicate. The limit of detection of epifluorescence counts was 60 cells/mL of detached biofilm.

\subsection{Real-Time RT-PCR Assays}

Total RNA was extracted from $5 \mathrm{~mL}$ of detached biofilm using the RNeasy Mini Kit (Qiagen, Hilden, Germany), as described previously [21]. Total RNA was retro-transcribed using Qiagen's QuantiTect Reserve Transcription kit.

Real-time PCRs were carried out in a total volume of $20 \mu \mathrm{L}$ containing $0.25 \mu \mathrm{M}$ of each primer (Table 3), $10 \mu \mathrm{L}$ of $2 \times$ Supermix (Qiagen) and $2 \mu \mathrm{L}$ of reverse transcription mixture. Cycling conditions were $95{ }^{\circ} \mathrm{C}$ for $3 \mathrm{~min}$, followed by 40 cycles of $95{ }^{\circ} \mathrm{C}$ for $10 \mathrm{~s}$, different annealing temperatures (Table 3) for $20 \mathrm{~s}$ and $72{ }^{\circ} \mathrm{C}$ for $20 \mathrm{~s}$. Amplification reactions and melt-curve analysis were performed using the Rotor-Gene Q MDx (Qiagen). cDNA obtained starting from a broth culture of $S$. aureus 10850 was used as a positive control.

Table 3. Target genes and primer pairs used in gene expression assays.

\begin{tabular}{|c|c|c|c|c|c|}
\hline $\begin{array}{l}\text { Target } \\
\text { Gene }\end{array}$ & Gene Function & Primer Pair (5'-3') & $\begin{array}{c}\text { Annealing } \\
\text { Temperature } \\
\left({ }^{\circ} \mathrm{C}\right) \\
\end{array}$ & $\begin{array}{l}\text { Product } \\
\text { Size (bp) }\end{array}$ & Reference \\
\hline $16 S r D N A$ & Housekeeping & $\begin{array}{l}\text { F-TGGAGCATGTGGTTTAATTCGA } \\
\text { R-TGCGGGACTTAACCCAACA }\end{array}$ & 60 & 159 & {$[32]$} \\
\hline glt & $\begin{array}{l}\text { Species specific, } \\
\text { coding for } \\
\text { glutamate synthase }\end{array}$ & $\begin{array}{c}\text { F-AATCTTTGTCGGTACA } \\
\text { CGATATTCTTCACG } \\
\text { R-CGTAATGAGATTTCA } \\
\text { GTAGATAATACAACA }\end{array}$ & 58 & 108 & {$[33]$} \\
\hline nuc & $\begin{array}{l}\text { Virulence factor, } \\
\text { coding for } \\
\text { thermonuclease }\end{array}$ & $\begin{array}{l}\text { F-GACTATTATTGGTTGATCCACCTG } \\
\text { R- GCCTTGACGAACTAAAGCTTCG }\end{array}$ & 60 & 218 & {$[34]$} \\
\hline mecA & $\begin{array}{l}\text { Methicillin } \\
\text { resistance }\end{array}$ & $\begin{array}{c}\text { F-TCCAGATTACAACTTCACCAGG } \\
\text { R-CCACTTCATATCTTGTAACG }\end{array}$ & 57 & 162 & {$[35]$} \\
\hline
\end{tabular}

\section{Conclusions}

The present findings provide evidence that daptomycin may play a role in the induction and persistence of VBNC $S$. aureus biofilms by showing cell viability and gene expression for months after achievement of non-culturability. Infections caused by staphylococcal biofilms should be treated by carefully selected and dosed antibiotics, to maintain drug concentrations capable of exerting full inhibitory activity. The ability of non-culturable daptomycin-exposed staphylococcal biofilms to resuscitate requires additional testing. Further experiments are under way in our laboratory. 


\section{Acknowledgments}

The authors are grateful to Sofia Giaconi for biofilm preparation and technical assistance.

\section{Author Contributions}

Sonia Pasquaroli designed the experiments, cultured the biofilms, performed RNA extractions, epifluorescence and cytofluorimetric counts and wrote the paper draft. Barbara Citterio contributed to monitoring non-culturability, to extracting RNA from non-culturable biofilms and to performing retro-transcription assays. Andrea Di Cesare and Mehdi Amiri performed the RT-PCR assays and analyzed the data. Anita Manti performed the cytofluorimetric analyses. Claudia Vuotto analyzed the biofilm production by SEM. Francesca Biavasco conceived of the experiments, analyzed the data and wrote the paper.

\section{Conflicts of Interest}

The authors have no conflicts of interest.

\section{References}

1. Donlan, R.; Costerton, J. Biofilms: survival mechanisms of clinically relevant microorganisms. Clin. Microbiol. Rev. 2002, 15, 167-193.

2. Hall-Stoodley, L.; Stoodley, P. Evolving concepts in biofilm infections. Cell. Microbiol. 2009, 11, 1034-1043.

3. Francolini, I.; Donelli, G. Prevention and control of biofilm-based medical- device-related infections. FEMS Immunol. Med. Microbiol. 2010, 59, 227-238.

4. Zandri, G.; Pasquaroli, S.; Vignaroli, C.; Talevi, S.; Manso, E.; Donelli, G.; Biavasco, F. Detection of viable but non-culturable staphylococci in biofilms from central venous catheters negative on standard microbiological assays. Clin. Microbiol. Infect. 2012, 18, 259-261.

5. Chambers, H.F. Methicillin resistance in staphylococci: Molecular and biochemical basis and clinical implications. Clin. Microbiol. Rev. 1997, 10, 781-791.

6. Enoch, D.A.; Bygott, J.M.; Daly, M.L.; Karas, J.A. Daptomycin. J. Infect. 2007, 55, 205-213.

7. Tarai, B.; Das, P.; Kumar, D. Recurrent challenges for clinicians: Emergence of methicillin-resistant Staphylococcus aureus, vancomycin resistance, and current treatment options. J. Lab. Phys. 2013, 5, 71-78.

8. Popiel, K.Y.; Miller, M.A. Evaluation of Vancomycin-Resistant Enterococci (VRE)-associated morbidity following relaxation of VRE screening and isolation precautions in a tertiary care hospital. Infect. Control Hosp. Epidemiol. 2014, 35, 818-825.

9. Carugati, M.; Bayer, A.S.; Miró, J.M.; Park, L.P.; Guimarães, A.C.; Skoutelis, A.; Fortes, C.Q.; Durante-Mangoni, E.; Hannan, M.M.; Nacinovich, F.; et al. High-Dose daptomycin therapy for left-sided infective endocarditis: A prospective study from the international collaboration on endocarditis. Antimicrob. Agents Chemother. 2013, 57, 6213-6222.

10. Robbel, L.; Marahiel, M.A. Daptomycin, a bacterial lipopeptide synthesized by a nonribosomal machinery. J. Biol. Chem. 2010, 285, 27501-27508. 
11. Raad, I.; Hanna, H.; Jiang, Y.; Dvorak, T.; Reitzel, R.; Chaiban, G.; Sherertz, R.; Hachem, R. Comparative activities of daptomycin, linezolid, and tigecycline against catheter-related methicillin-resistant Staphylococcus bacteremic isolates embedded in biofilm. Antimicrob. Agents Chemother. 2007, 51, 1656-1660.

12. Barber, K.E.; Werth, B.J.; McRoberts, J.P.; Rybak, M.J. A novel approach utilizing biofilm time-kill curves to assess the bactericidal activity of ceftaroline combinations against biofilm-producing methicillin-resistant Staphylococcus aureus. Antimicrob. Agents Chemother. 2014, 58, 2989-2992.

13. Len, O.; Montejo, M.; Cervera, C.; Fariñas, M.C.; Sabé, N.; Ramos, A.; Cordero, E.; Torre-Cisneros, J.; Martín-Dávila, P.; Azanza, J.R.; et al. Daptomycin is safe and effective for the treatment of gram-positive cocci infections in solid organ transplantation. Transpl. Infect. Dis. 2014, doi:10.1111/tid.12232.

14. Vilhena, C.; Bettencourt, A. Daptomycin: A review of properties, clinical use, drug delivery and resistance. Mini Rev. Med. Chem. 2012, 12, 202-209.

15. Kelesidis, T. The interplay between daptomycin and the immune system. Front. Immunol. 2014, 5,52 .

16. Agarwal, A.; Singh, K.P.; Jain, A. Medical significance and management of staphylococcal biofilm. FEMS Immunol. Med. Microbiol. 2010, 58, 147-160.

17. Meije, Y.; Almirante, B.; del Pozo, J.L.; Martín, M.T.; Fernández-Hidalgo, N.; Shan, A.; Basas, J.; Pahissa, A.; Gavaldà, J. Daptomycin is effective as antibiotic-lock therapy in a model of Staphylococcus aureus catheter-related infection. J. Infect. 2014, 68, 548-552.

18. Holmberg, A.; Rasmussen, M. Antibiotic regimens with rifampicin for treatment of Enterococcus faecium in biofilms. Int. J. Antimicrob. Agents 2014, 44, 78-80.

19. Oliver, J.D. Recent findings on the viable but non-culturable state in pathogenic bacteria. FEMS Microbiol. Rev. 2009, 34, 415-425.

20. Nowakowska, J.; Oliver, J.D. Resistance to environmental stresses by Vibrio vulnificus in the viable but non-culturable state. FEMS Microbiol. Ecol. 2013, 84, 213-222.

21. Pasquaroli, S.; Zandri, G.; Vignaroli, C.; Vuotto, C.; Donelli, G.; Biavasco, F. Antibiotic pressure can induce the viable but non-culturable state in Staphylococcus aureus growing in biofilms. J. Antimicrob. Chemother. 2013, 68, 1812-1817.

22. Pascoe, B.; Dams, L.; Wilkinson, T.S.; Harris, L.G.; Bodger, O.; Mack, D.; Davies, A.P. Dormant cells of Staphylococcus aureus are resuscitated by spent culture supernatant. PLoS One 2014, 9, e85998.

23. El-Azizi, M.; Rao, S.; Kanchanapoom, T.; Khardori, N. In vitro activity of vancomycin, quinupristin/dalfopristin, and linezolid against intact and disrupted biofilms of staphylococci. Ann. Clin. Microbiol. Antimicrob. 2005, 4, 2.

24. Donelli, G.; Francolini, I.; Romoli, D.; Guaglianone, E.; Piozzi, A.; Ragunath, C.; Kaplan, J.B. Synergistic activity of dispersin B and cefamandole nafate in inhibition of staphylococcal biofilm growth on polyurethanes. Antimicrob. Agents Chemother. 2007, 51, 2733-2740.

25. Lahtinen, S.J.; Ahokoski, H.; Reinikainen, J.P.; Gueimonde, M.; Nurmi, J.; Ouwehand, A.C.; Salminen, S.J. Degradation of $16 \mathrm{~S}$ rRNA and attributes of viability of viable but non-culturable probiotic bacteria. Lett. Appl. Microbiol. 2008, 46, 693-698. 
26. Wiltshire, M.D.; Foster, S.J. Identification and analysis of Staphylococcus aureus components expressed by a model system of growth in serum. Infect. Immun. 2001, 69, 5198-5202.

27. Rahman, I.; Shahamat, M.; Kirchman, P.A.; Russek-Cohen, E.; Colwell, R.R. Methionine uptake and cytopathogenicity of viable but non-culturable Shigella dysenteriae type 1. Appl. Environ. Microb. 1994, 60, 3573-3578.

28. Kiedrowski, M.R.; Kavanaugh, J.S.; Malone, C.L.; Mootz, J.M.; Voyich, J.M.; Smeltzer, M.S.; Bayles, K.W.; Horswill, A.R. Nuclease modulates biofilm formation in community-associated methicillin-resistant Staphylococcus aureus. PLoS One 2011, 6, e26714.

29. Sengupta, S.; Chattopadhyay, M.K.; Grossart, H.P. The multifaceted roles of antibiotics and antibiotic resistance in nature. Front. Microbiol. 2013, 4, 47.

30. Davies, J.; Spiegelman, G.B.; Yim, G. The world of subinhibitory antibiotic concentrations. Curr. Opin. Microbiol. 2006, 9, 445-453.

31. The European Committee on Antimicrobial Susceptibility Testing. Breakpoint tables for interpretation of MICs and zone diameters.Version 4.0, 2014. Available online: http://www.eucast.org (accessed on 17 September 2014).

32. Warwick, S.; Wilks, M.; Hennessy, E.; Powell-Tuck, J.; Small, M.; Sharp, J.; Millar, M.R. Use of quantitative $16 \mathrm{~S}$ ribosomal DNA detection for diagnosis of central vascular catheter-associated bacterial infection. J. Clin. Microbiol. 2004, 42, 1402-1408.

33. Martineau, F.; Picard, F.J.; Roy, P.H.; Ouellette, M.; Bergeron, M.G. Species-Specific and ubiquitous-DNA-based assays for rapid identification of Staphylococcus aureus. J. Clin. Microbiol. 1998, 36, 618-623.

34. Depardieu, F.; Perichon, B.; Courvalin, P. Detection of the van alphabet and identification of enterococci and staphylococci at the species level by multiplex PCR. J. Clin. Microbiol. 2004, 42, 5857-5860.

35. Oliveira, D.C.; Milheiric, C.; de Lencastre, H. Update to the multiplex PCR strategy for assignment of mec element types in Staphylococcus aureus. Antimicrob. Agents Chemother. 2007, $51,3374-3377$.

(C) 2014 by the authors; licensee MDPI, Basel, Switzerland. This article is an open access article distributed under the terms and conditions of the Creative Commons Attribution license (http://creativecommons.org/licenses/by/3.0/). 